\title{
A comparative study of different methods of processing aortic homografts
}

\author{
W. WELCH${ }^{1}$ \\ From the National Heart Hospital, London
}

\begin{abstract}
Segments of the same aortic cusp were processed in different ways and compared from a histological and histochemical point of view with a non-processed segment. Changes produced by certain methods of processing bear a resemblance to the changes noted in the normal ageing process of the aortic valves. These changes are commented upon; but further experimental work is necessary to determine which method of processing aortic homografts gives the best long-term results.
\end{abstract}

Since Ross (1964) and Barratt-Boyes (1964) first advocated the replacement of diseased aortic valves with homografts and published their results, the use of these grafts has become widespread.

One finds in the literature different ways of processing valves (Barratt-Boyes, 1964 ; Longmore, Lockey, Ross, and Pickering, 1966 ; O'Brien, 1967 ; Bentall, 1967 ; Harris, Kovalik, Marks, and Malm, 1968) ; but very little is written about the influence of these methods on the structure of the aortic valve (Duran and Gunning, 1962 ; Harris et al., 1968).

Hudson (1966), Lower, Pillsbury, Angell, and Kosek (1966), and Smith (1967) have studied the fate of homografts in the human but have not referred to the histological changes produced by processing these grafts.

\section{METHOD}

Forty-nine aortic valves were studied. These were obtained from necropsy specimens and complied with the criteria used in the selection of homografts (Longmore et al., 1966). The valves were opened by cutting the aorta along the commissure between the left and right coronary cusps. Each cusp was consequently cut in four sections, one of which was retained and not processed, whereas the others were processed in different ways (Fig. 1). The following methods of processing were used:

1. Ethylene oxide sterilization, freeze-drying, and storage at room temperature (Longmore et al., 1966);

2. Ethylene oxide sterilization, flash-freezing in Cardice and acetone with storage at $-79^{\circ}$ (Ross, 1967) ;

1 Present address : Department of Cardiac Surgery, Brugmann University Hospital, 4 Place van Gehuchten, Brussels 2, Belgium.
3. Sterilization and storage in buffered formalin (O’Brien, 1967) ;

4. Sterilization in a $1 \%$ aqueous solution of $\beta$-propiolactone and storage in Hank's solution (Bentall, 1967).

5. $\gamma$-ray (Gibbons, 1967) and electron beam sterilization at $-79^{\circ}$ (Harris et al., 1968) with storage at the same temperature.

Sections were stained with haematoxylin and eosin $\stackrel{\unrhd}{\unrhd}$ periodic acid-Schiff, toluidine blue, colloidal iron and $\overrightarrow{\vec{O}}$ alcian blue, and Verhoeff-van Gieson elastic tissue 3 method (Pearse, 1960).

The skeleton of the cusp is the fibrosa, which is the continuation of the annulus fibrosus and is음 formed mainly of collagen. On the aortic and $\tilde{N}_{x}$ ventricular aspects are found, respectively, the arterialis and the ventricularis, which consist of endothelium covering layers of elastic tissue (Fig.ô 2). Elastic tissue is more abundant in the ventricu laris. The spongiosa at the base of the cusp is? formed of loose connective tissue. With the excep- $\rightarrow$ tion of the endothelial layer, the whole of the adult aortic cusp is poor in cells, some fibroblasts being present in the annulus fibrosus and the fibrosa. All nuclei are stained darkly and corre ${ }_{0}^{N}$ spond to images of pyknosis.

Collagen fibres are placed in an orderly mannee in the annulus and the fibrosa and are eosinose philic. There is also collagen present between theD laminae of elastic tissue of the arterialis and ven tricularis.

Positive P.A.S.-staining material is found in the्ष fibrous tissue and between the elastic laminae.

Interfibrillar material, mainly in the ventricu laris, stained with alcian blue and colloidal irop 


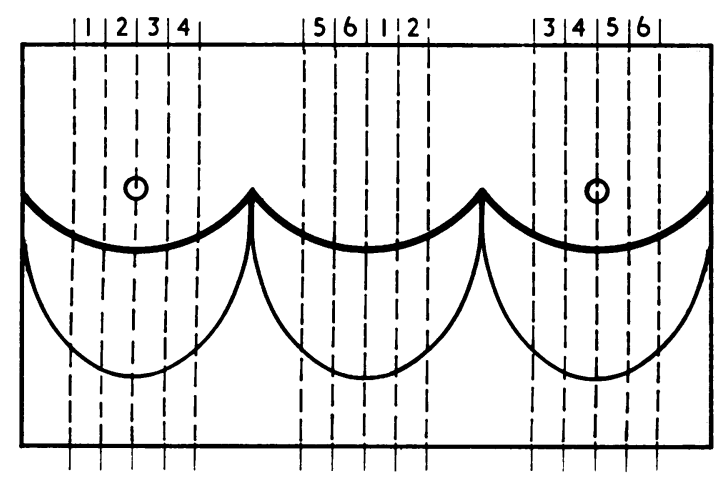

FIG. 1. (1) Non-processed; (2) Ethylene oxide, freezedried; (3) Ethylene oxide, flash-frozen; (4) Buffered formalin; (5) $\beta$-propiolactone; (6) Irradiation.

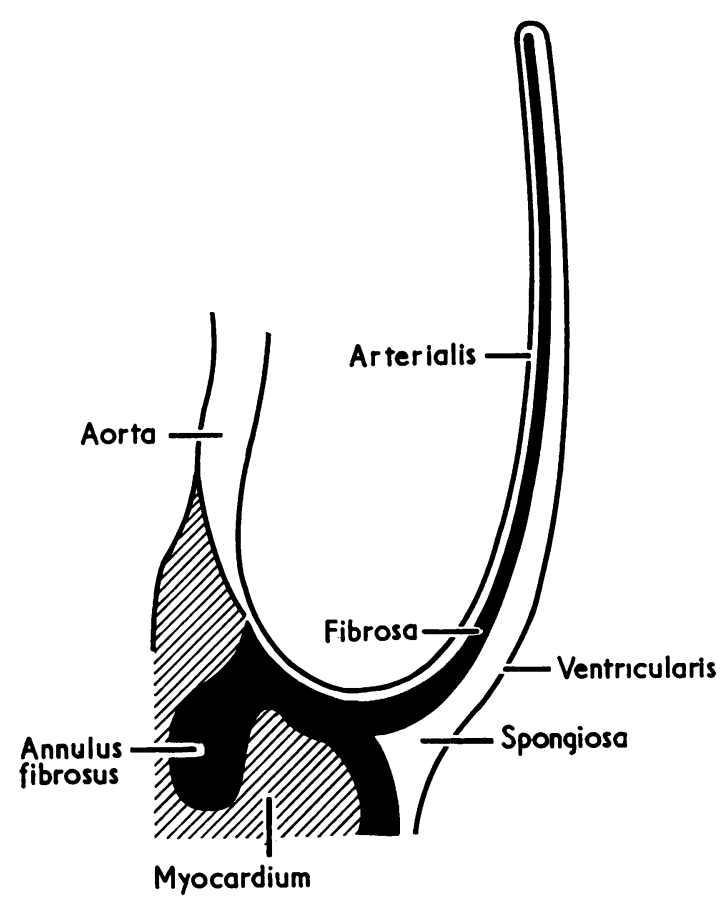

FIG. 2. Schematic section of the aortic valve.

and metachromatically with toluidine blue indicates the presence of acid mucopolysaccharides. Metachromasia is most marked in the loose connective tissue of the spongiosa at the base of the cusp.

The chemical properties of the elastic tissue of the aortic wall and cusp differ as shown in the course of the normal ageing process and the formation of atheroma in these structures (Sell and Scully, 1965).

Flash-freezing, buffered formalin, and irradiation do not seem to alter either the basic structure of the valve or the histochemical aspects that we have studied. No distinction is made between $\gamma$-rayed and electron beam irradiated material, as no histological difference is found between them (Fig. 3).

About two-thirds of the freeze-dried valves have vacuoles in the annulus and the fibrosa at the base of the cusp.

Processing with $\beta$-propiolactone produces major changes. Constantly the laminated structure of the collagen fibres disappears and is replaced by an amorphous mass of eosinophilic material. The positive P.A.S.-stained material decreases markedly and the whole cusp loses its content of acid mucopolysaccharides (Fig. 3).

The changes produced in a processed valve compared to a fresh valve can be assessed arbitrarily and graded from 1 to 10 (Table). This shows that valves processed with $\beta$-propiolactone are the most modified, whereas freeze-drying also produces some alterations.

T A B L E

\begin{tabular}{l|c|c|c|c|c|c}
\hline & $\begin{array}{c}\text { Cyto- } \\
\text { logy }\end{array}$ & Collagen & $\begin{array}{c}\text { Elastic } \\
\text { Tissue }\end{array}$ & $\begin{array}{c}\text { Muco- } \\
\text { proteins }\end{array}$ & A.M.P.S. & Total \\
\hline $\begin{array}{c}\text { Ethylene oxide, } \\
\text { freeze-dried }\end{array}$ & 0 & 3 & 0 & 3 & 3 & 9 \\
$\begin{array}{c}\text { Ethylene oxide, } \\
\text { flash-frozen }\end{array}$ & 0 & 0 & 0 & 0 & 0 & 0 \\
$\begin{array}{c}\text { Buffered } \\
\text { formalin }\end{array}$ & 0 & 0 & 0 & 0 & 0 & 0 \\
$\begin{array}{c}\beta \text {-propiolactone } \\
\text { Irradiation }\end{array}$ & $\mathbf{0}$ & $\mathbf{0}$ & $\mathbf{3}$ & $\mathbf{9}$ & $\mathbf{9}$ & $\mathbf{2 7}$ \\
\hline
\end{tabular}

The effect of physical agents must also be taken into consideration. As Pickering (1966) states and as we also find, repeated freezing and thawing, which occurs when valves are reprocessed, disrupts the laminated structures of the collagen in the cusps. When using irradiation to sterilize a valve, the irradiation dose must be precisely controlled. By over-irradiating, the structure is completely altered, nuclei disappear, and collagen is reduced to an amorphous mass.

The conclusions that one draws from these findings can only be speculative and it is impossible to determine from them which of the methods of processing will give the best long-term results in valvular replacement. However, as Sell and Scully (1965) have shown, alterations in the 

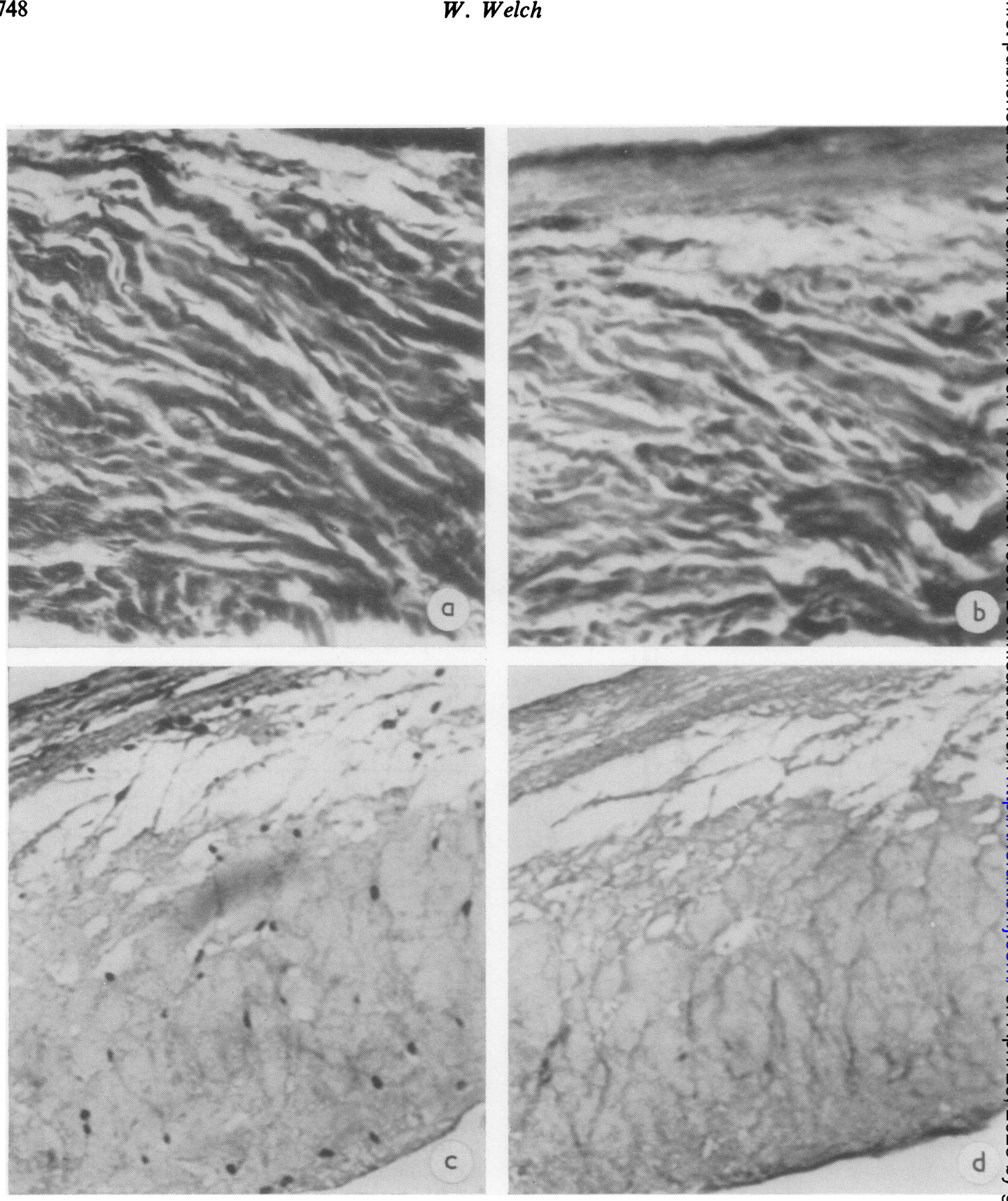

FIG. 3. Sections of a right coronary cusp. (a) Cusp processed with buffered formalin:laminated structure of elastic tissue and collagen, comparable to the structure of a fresh cusp (Verhoeff-Van Gieson). (b) Cusp processed with buffered form alin:P.A.S.-positive material in the elastica and fibrosa, comparable to the structure of a fresh cusp (Periodic acie Schiff). (c) Cusp processed with $\beta$-propiolactone and preserved in Hank's solution at $4^{\circ} C$. Vacuoles are present be tween the layers of elastic tissue and in the fibrosa. Disappearance of the laminated structure of the collagen (Verhoef Van Gieson). (d) Cusp processed with $\beta$-propiolactone and preserved in Hank's solution at $4^{\circ}$ C. Reduction of P.A.S positive material in the fibrosa and disappearance of the laminated structure (Periodic acid-Schiff). 
structure of collagen fibres are precursory signs of calcification seen in the normal ageing process of aortic valves. A decrease in acid-mucopolysaccharides has also been noted in the chemical analysis of ageing bovine cardiac valves (Jacobson and Boström, 1964). A further experimental study is necessary to determine whether the integrity of the aortic valve influences its uptake by the host and whether the different methods of processing influence the long-term results of aortic valve replacement.

This work was supported by grants from the British Heart Foundation and from the Fonds de la Recherche Scientifique Médicale.

\section{REFERENCES}

Barratt-Boyes, B. G. (1964). Homograft aortic valve replacement in aortic incompetence and stenosis. Thorax, 19, 131 .

Bentall, H. H. (1967). Personal communication, June 1967.

Duran, C. G., and Gunning, A. J. (1962). A method for placing a total homologous aortic valve in the subcoronary position. Lancet, 2, 488.
Gibbons, J. (1967). Gamma ray sterilized homograft valve. Proc. Int. Atomic Energy Agency, Vienna, June.

Harris, P. D., Kovalik, A. T. W., Marks, J. A., and Malm, J. R. (1968). Factors modifying aortic homograft structure and function. Surgery, 63, 45.

Hudson, R. E. B. (1966). Pathology of the human aortic valve homograft. Brit. Heart J., 28, 291.

Jacobson, B., and Boström, H. (1964). Studies on the biochemistry of heart valves. II. The effect of aging and anti-inflammatory drugs on the synthesis of glucosamine 6-phosphate and phos-
phoadenosine phosphosulfate by bovine heart valves. Biochem. biophys. Acta, 83, 152.

Longmore, D. B., Lockey E., Ross, D. N., and Pickering, B. N. (1966). The preparation of aortic-valve homografts. Lancet, 2,463

Lower, R. R., Pillsbury, R. C., Angell, W. W., and Kosek, J. C. (1966). Homograft heart valves. Circulation, 33, Supplement 1 , p. 135.

O'Brien, M. F. (1967). Heterograft aortic valves for human use. J. thorac. cardiovasc. Surg., 53, 392.

Pearse, A. G. Emerson (1960). Histochemistry, Theoretical and Applied, 2nd ed. J. and A. Churchill, London.

Pickering, B. (1966). The preparation and storage of aortic valve homografts. Guy's Hosp. Rep., 115, 105.

Ross, D. (1964). Homotransplantation of the aortic valve in the subcoronary position. J. thorac. cardiovasc. Surg., 47, 713. (1967). Personal communication.

Sell, S., and Scully, R. E. (1965). Aging changes in the aortic and mitral valves. Amer. J. Path., 46, 345.

Smith, J. C. (1967). The pathology of human aortic valve homografts. Thorax, 22, 114. 